\title{
SETTING LIQUID LEVEL COUPLED TANK USING FUZZY ADAPTIVE CONTROL
}

\author{
Mohammad Erik Echsony, Noorsakti Wahyudi, Nur Asyik Hidayatullah
}

\begin{abstract}
The problem with Coupled Tanks is the appearance of interference in the flow that supplies the tank will make the response unstable, resulting in crossinteraction between each input and output. Fuzzy Logic Control (FLC) has its own advantages that is effective in dealing with complex non-linear systems. Adaptive Fuzzy control Auto tuning has the ability to maintain the steady state response value from interference. Adaptive Fuzzy methodology is attractive choice when formulation in the method proposed for the Coupled tank process. Adaptive Fuzzy control has the ability to maintain the steady state response value from interference. In this study using decoupling in the cross interaction process in each tank. Coupled Tanks on the TITO system can change the transfer function to SISO, so as to minimize the effect of interacting. The right way to design modeling is to pay attention to the state of the plant, so that the desired control model can overcome the non linearity of the TITO system. Adaptive Fuzzy method expected to have percent overshoot and better settling time value.
\end{abstract}

Index Terms-Coupled Tanks, System, TITO, Fuzzy, Adaptive..

\section{INTRODUCTION}

I ndustrial process many use horizontal tanks for oil or chemical liquids. Level control is used to maintain the set level point for a given value so that it can receive setting point values dynamically. In the fluid industry process, one of the most common problems is the control of Coupled Tank level [1]. Generally, there are two methods for designing a controller for the TITO process. First, the modern method, using a centralized / single and second controller, the classical method, uses decentralized controllers.

There are two methods for designing a controller for the TITO process. First, the modern method, using a centralized / single and second controller, the classical method, uses decentralized controllers. Constraints in Coupled Tank level control are the appearance of interference in the flow that supplies the tank will make the response unstable so that the appropriate control

Mohammad erik echsony is a lecturer in the Computer Control Engineering program, Politeknik Negeri Madiun (Phone 081233650810; email: erik_sony@pnm.ac.id)

Noorsakti Wahyudi is a lecturer in the automotive enginering Politeknik Negeri Madiun (Phone: 0821411003524; email: oorsakti@pnm.ac.id)

Nur Asyik Hidayatullah is a lecturer in the Electrical Engineering program, Politeknik Negeri Madiun (Phone: 082233107171; email: asyik@pnm.ac.id) method is needed. The problem often faced is that this control system requires more complex knowledge about parameters related system. The problem will be more complicated if used for complex systems [2]. Characteristic Ratio Assessment (CRA) is a method of solving problems at the Two Input Two Output (TITO) plant by using a pole placement defined parameter equation characteristics.

This method allows to adjust the response speed and damping ratio using only one parameter. To make the plant into a Coupled Input Coupled Output (SISO), the Decoupling method is used so that the input effect of both tanks can be reduced by CRA resulting in a better response than the PID control [3]. The overall PI control element aims to accelerate the reaction of a system and eliminate offsets [4].

\section{METHODOLOGY}

\section{A. Modeling Coupled Tanks Coupled Tanks}

Composed of two tanks connected by a pipe or drain hole. The liquid level in the first tank is shown as H1 and $\mathrm{H} 2$ is the second tank level. If the control input is flow Q1, then the variables to be controlled are both $\mathrm{H} 1$ and $\mathrm{H} 2$ levels, with a disturbance caused by variations in flow in valve A, valve B. Here there will be a sustu system with two tanks interacting [5].

The Coupled Tanks system can be configured as a SISO system or as a TITO System through input pump manipulation and sectional area valve. Given the mass balance, the dynamic equation of each tank is formulated [6].

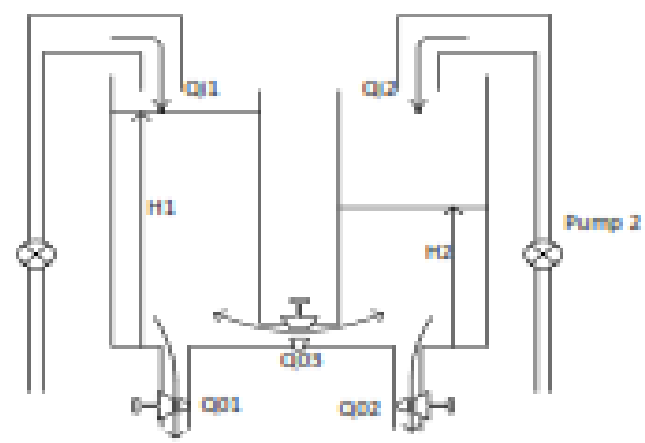

Figure 1 Coupled tanks system

$A_{1} \frac{d H_{1}}{d t}=Q_{i 1}-Q_{01}-Q_{03}$ 


$$
\begin{aligned}
& A_{2} \frac{d H_{2}}{d t}=Q_{i 2}-Q_{02}+Q_{03} \\
& Q_{01}=s_{1} \cdot a_{0} \sqrt{2 g} \cdot \sqrt{H_{1}}=\alpha_{1} \cdot \sqrt{H_{1}} \\
& Q_{02}=s_{2} \cdot a_{0} \sqrt{2 g} \cdot \sqrt{H_{2}}=\alpha_{2} \cdot \sqrt{H_{2}} \\
& Q_{03}=s_{1} \cdot a_{0} \sqrt{2 g} \cdot \sqrt{H_{1}-H_{2}}=\alpha_{3} \cdot \sqrt{H_{1}-H_{2}}
\end{aligned}
$$

Using values from equations (3) to (5) into equations (1) and (2) obtained by nonlinear equations that describe the dynamics of multi-input and multi-output systems derived:

$A_{1} \frac{d H_{1}}{d t}=Q_{i 1}-\alpha_{1} \cdot \sqrt{H_{1}}-\alpha_{3} \cdot \sqrt{H_{1}-H_{2}}$

$A_{2} \frac{d H_{2}}{d t}=Q_{i 2}-\alpha_{2} \cdot \sqrt{H_{2}}+\alpha_{3} \cdot \sqrt{H_{1}-H_{2}}$

Model linearisasi Two Input-Two Output (TITO).

$A_{1} \frac{d H_{1}}{d t}=Q_{i 1}-\alpha_{3} \cdot \sqrt{H_{1}-H_{2}}$

$A_{2} \frac{d H_{2}}{d t}=\alpha_{2} \cdot \sqrt{H_{2}}+\alpha_{3} \cdot \sqrt{H_{1}-H_{2}}$

B. Diagram Blok Sytem TITO

$$
\left[\begin{array}{l}
H_{1}(s) \\
H_{2}(s)
\end{array}\right]=\left[\begin{array}{ll}
G_{11}(s) & G_{12}(s) \\
G_{21}(s) & G_{22}(s)
\end{array}\right] \cdot\left[\begin{array}{c}
U_{1}(s) \\
U_{2}(s)
\end{array}\right]
$$

$$
\begin{aligned}
& G_{11}(s)=\frac{\frac{k_{1}}{A}\left(s+\frac{T_{x}+T_{2}}{T_{2} T_{x}}\right)}{s^{2}+\left(\frac{T_{1} T_{x}+T_{2} T_{x}+2 T_{1} T_{2}}{T_{1} T_{2} T_{x}}\right) s+\left(\frac{1}{T_{1} T_{2}}+\frac{1}{T_{1} T_{x}}+\frac{1}{T_{2} T_{x}}\right)} \\
& G_{11}(s)=\frac{\frac{k_{1}}{A}\left(s+\frac{T_{x}+T_{2}}{T_{2} T_{x}}\right)}{s^{2}+\left(\frac{T_{1} T_{x}+T_{2} T_{x}+2 T_{1} T_{2}}{T_{1} T_{2} T_{x}}\right) s+\left(\frac{1}{T_{1} T_{2}}+\frac{1}{T_{1} T_{x}}+\frac{1}{T_{2} T_{x}}\right)} \\
& G_{12}(s)=\frac{k_{2} \cdot \frac{1}{T_{x}}}{s^{2}+\left(\frac{T_{1} T_{x}+T_{2} T_{x}+2 T_{1} T_{2}}{T_{1} T_{2} T_{x}}\right) s+\left(\frac{1}{T_{1} T_{2}}+\frac{1}{T_{1} T_{x}}+\frac{1}{T_{2} T_{x}}\right)} \\
& G_{22}(s)=\frac{\frac{k_{1}}{A} \cdot \frac{1}{T_{x}}}{s^{2}+\left(\frac{T_{1} T_{x}+T_{2} T_{x}+2 T_{1} T_{2}}{T_{1} T_{2} T_{x}}\right) s+\left(\frac{1}{T_{1} T_{2}}+\frac{1}{T_{1} T_{x}}+\frac{1}{T_{2} T_{x}}\right)} \\
& \frac{k_{2}}{A}\left(s+\frac{T_{x}+T_{1}}{T_{1} T_{x}}\right)
\end{aligned}
$$




\section{Adaptive Fuzzy Controller}

The process is controlled by a fuzzy adaptive controller by updating its membership function. This is shown in Figure 2

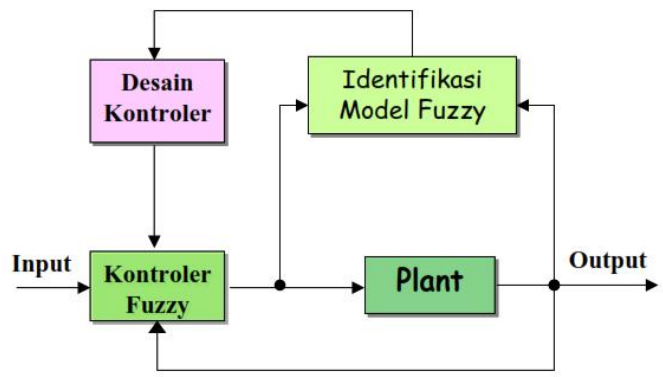

Figure 2 Fuzzy adaptive block diagram by updating its membership function

identification of fuzzy models is known that

$$
f(x)=\frac{\sum_{l=1}^{M} \bar{y}^{l}\left[\prod_{i=1}^{N} \exp \left(-\left(\frac{x_{i}-\bar{x}_{i}^{l}}{\sigma_{i}^{l}}\right)^{2}\right)\right]}{\sum_{l=1}^{M}\left[\prod_{i=1}^{N} \exp \left(-\left(\frac{x_{i}-\bar{x}_{i}^{l}}{\sigma_{i}^{l}}\right)^{2}\right)\right]}
$$

using error criteria

$e^{p}=0.5\left[f\left(x^{p}\right)-y^{p}\right]^{2}$

The process of adaptation of each fuzzy parameter using a gradient decrease is obtained

$$
\frac{\partial e}{\partial \bar{y}^{l}}=(f-y) \frac{\partial f}{\partial a} \frac{\partial a}{\partial \bar{y}^{l}}=(f-y) \frac{1}{b} z^{l}
$$

And the adaptation for the midpoint parameter of the membership function in the output is obtained

$$
\bar{y}^{l}(q+1)=\bar{y}^{l}(q)-\alpha \frac{f-y}{b} z^{l}
$$

\section{C.1 FUZZYFICATION}

Fuzzification is transforming the input value into linguistic values. There are two input variables, namely error and differential error. Each input variable is mapped into five linguistic variables with a membership function (Membership Function) Triangle, namely Negative Big (NB), Negative Small (NS), Zero (Z), Positive Small (PS), and Positive Big (PB). Membernship Function (MF) for input and output variables can be seen in Figure 4

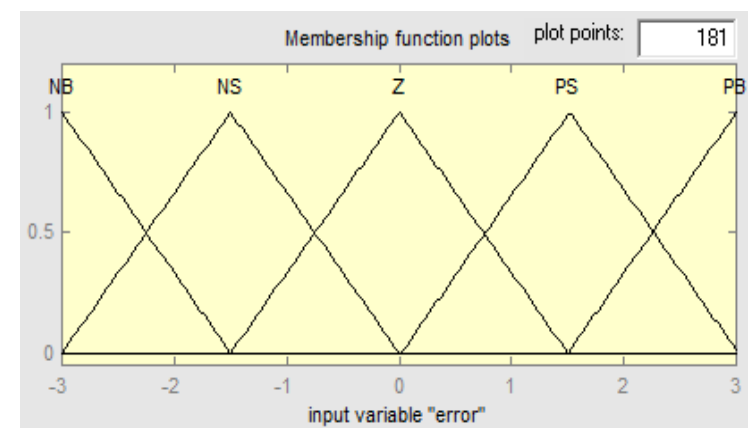

Figure 3 Membership function model for input error

Membership function is obtained from analyzing response parameters. Membership function has the same form as membership function error, this can be shown in Figure 4

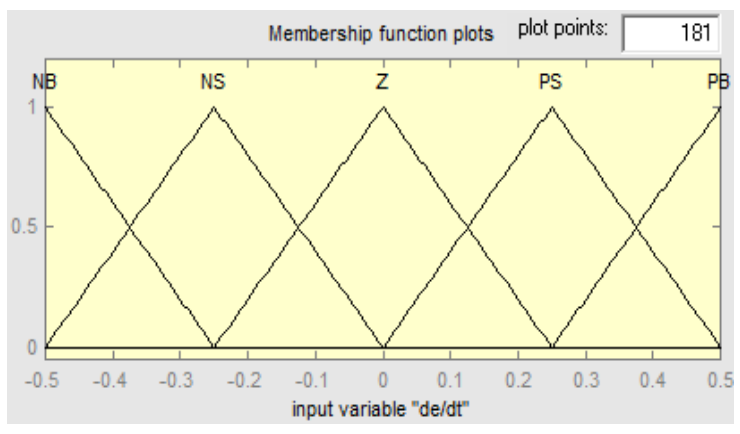

Figure 4 Diffrential error membership function model

\section{C.2. Rule Base}

Each rule occurs in an implication process that maps the degree of membership from the fuzification process to a fuzzy set which is the result of the implication process. The rule base for membership function outputs $\mathrm{Kp}$ and $\mathrm{Ki}$ using rules as shown in Table 3.

Table 3 Fuzzy Rule Base for control signals

\begin{tabular}{|c|c|c|c|c|c|c|}
\cline { 3 - 7 } \multicolumn{2}{c|}{} & \multicolumn{5}{c|}{$\mathrm{de} / \mathrm{dt}$} \\
\cline { 2 - 7 } \multicolumn{2}{c|}{} & NB & NS & Z & PS & PB \\
\hline \multirow{4}{*}{$\begin{array}{c}\text { error } \\
\text { (e) }\end{array}$} & NB & $Z$ & Z & PS & PS & PB \\
\cline { 2 - 7 } & NS & N & Z & Z & PS & PS \\
\cline { 2 - 7 } & Z & N & Z & Z & Z & N \\
\cline { 2 - 7 } & PS & PS & PS & Z & Z & N \\
\cline { 2 - 7 } & PB & PB & PS & PS & Z & Z \\
\hline
\end{tabular}

\section{Controller Design}

Based on the offline identification process, the transfer function equation is G11, G12, G21 and G22 respectively. After that, the decoupling mechanism of D12 and D21 was prepared to eliminate the influence of G12 and G21. Next, it is tested by open loop with a step signal on each desired tank level output. The results of this test will be used to design controller Adaptive fuzzy control using analytical methods. 


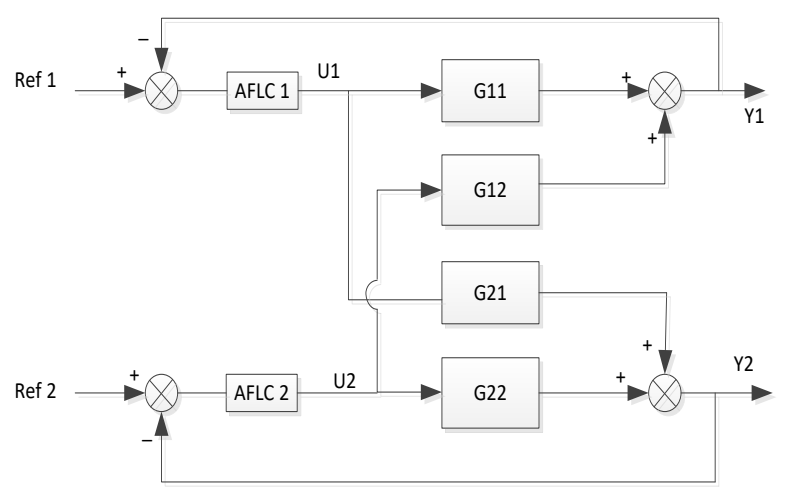

Figure 5 block diagram of designing a fuzzy adaptive controller

\section{RESULT AND ANALYSIS}

In the design simulation of this fuzzy adaptive controller comparison is used by using 2DOF-PI method and using adaptive fuzzy method. This comparison is applied to determine the difference in response between the two. As the reference level level for each tank will be given change according to time.

Table 4. Input Reference

\begin{tabular}{|l|c|c|c|c|}
\hline Time & $\mathrm{T}=0 \mathrm{~s}$ & $\mathrm{~T}=300 \mathrm{~s}$ & $\mathrm{~T}=600 \mathrm{~s}$ & $\mathrm{~T}=900 \mathrm{~s}$ \\
\hline Tanki 1 & 2 & 4 & 6 & 9 \\
\hline Tanki 2 & 2 & 3 & 5 & 10 \\
\hline
\end{tabular}

\section{Simulation Result}

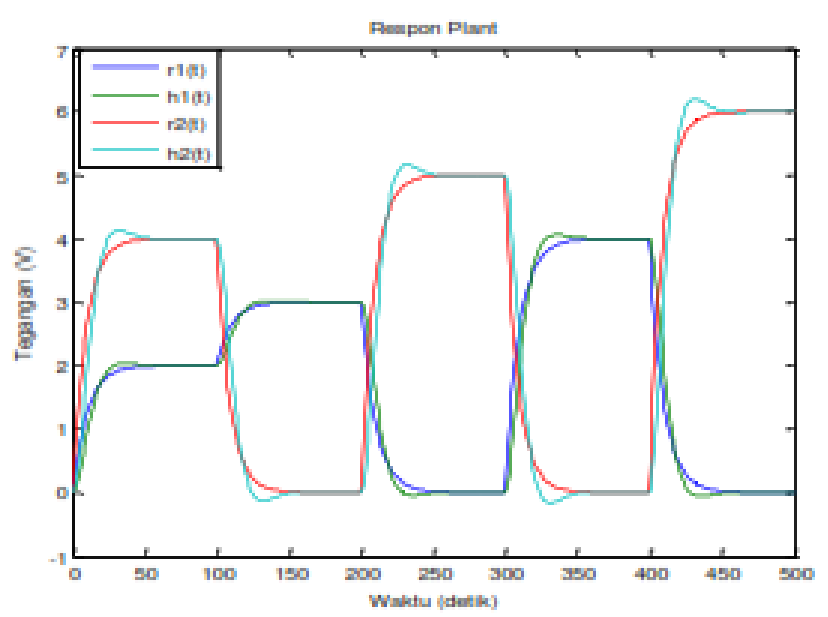

Figure 6. 2DOF-PI Control Response

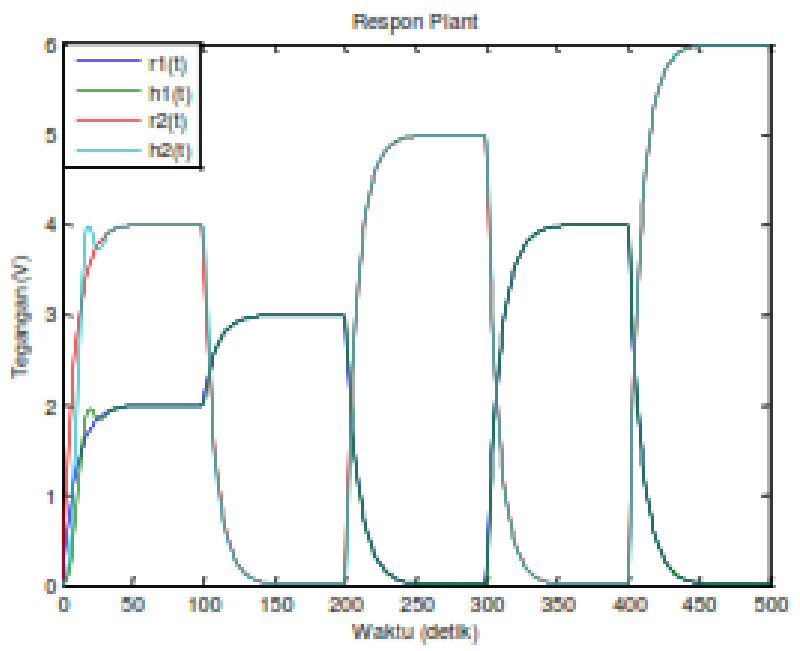

Figure 7. Adaptive Control Response to Fuzzy Auto tuning

In Figure 7, it is analyzed that the Fuzzy Adaptive control greatly affects the stability of Coupled-Tank so that the measured and realized level is very fast and the work response is fuzzy able to maintain the reference value that has been given

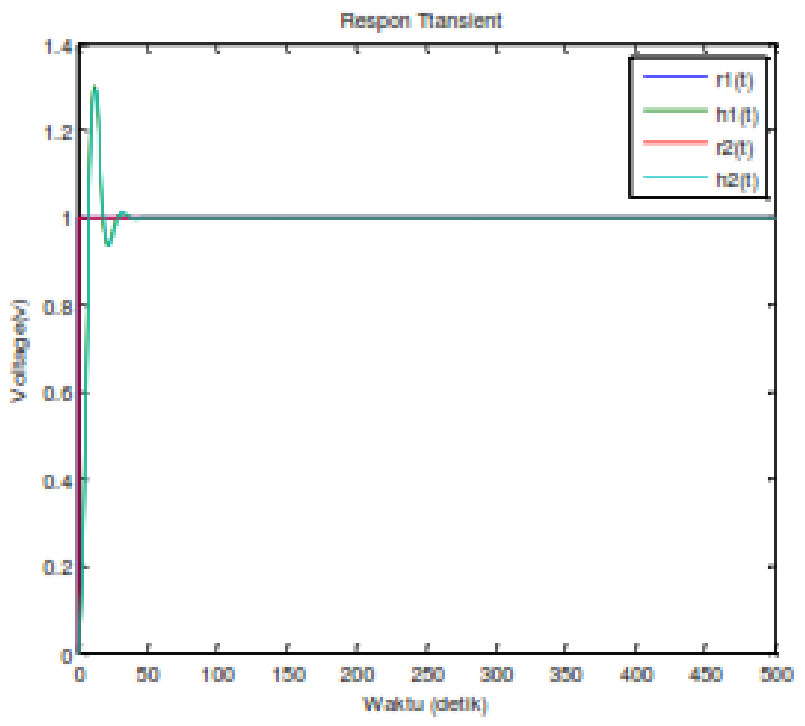

Figure 8. Transient response control system

In Figure 8 it is analyzed that the Fuzzy Adaptive control is very good transient response because overshot occurs at first, and then can overshot in the next wave phase.

Table 5. Transient response control system at $500 \mathrm{~s}$

\begin{tabular}{|c|c|c|}
\hline & $t_{s}(\mathrm{se})$ & P.O \\
\hline $\begin{array}{l}\text { Fuzzy PI auto tuning with } \\
\text { decoupling tank } 1\end{array}$ & 24 & 30 \\
\hline $\begin{array}{l}\text { Fuzzy PI auto tuning with } \\
\text { decoupling tank } 2\end{array}$ & 26 & 29 \\
\hline
\end{tabular}




\section{CONCLUSION}

Based on the research conducted, then can be concluded that;

1. The initial parameters in the plant modeling have $A\left(\mathrm{~cm}^{2}\right)=200, a\left(\mathrm{~cm}^{2}\right)=1.2661, \beta_{1}=1$, $\beta_{2}=1, \quad \beta_{x}=1$.

2. The use of the controller only has a maximum overshoot (Mp\%) - each tank is only <50\% (Stable state).

3. In the use of Fuzzy PI Auto-tuning controller by generating a settling time value (ts) which is better and faster than without decoupling.

4. Use of Adaptive Fuzzy Control is very good because overshoot occurs at first, and then can reduce overshot in the next phase.

5. The methodology used can still be developed for subsequent research, such as control, neural fuzzy, with CRA, MRAC, MPC, Decentralized FLC techniques.

\section{REFERENCES}

[1] Satean, T. Santi, W. (2006), "Level Control in Horizontal Tank by Fuzzy Logic Controller", SICE-ICASE International Joint Conference,24912494.

[2] Wahyudi, Iwan, S. Eduward, T. (2008), "Tuning Parameter Kontrol Proporsional - Integral Menggunakan Sugeno Fuzzy Inference System, ' Transmisi, Jurnal Teknik Elektro, Jilid 10, Nomor 2, hal. 97-102.

[3] Maruthai, S. Gunna, J.S. Ranganayhan, R.H. (2009), "Integrated Fuzzy Logic Based Intelligent Control of Three Tank System", Serbian Journal of Electrical Engineering, Vol.6, No. 1, 1-14.

[4] Arjin, N. Theeerachai, W. (2007), "Design of Decoupled Controller for TITO System using Characteristic Ratio Assignment", International Conference on Control Automation and Systems, 957-962.

[5] Abdulhakim, K. Ercument, K. (2008), "Performance Analysis of PM Synchronous Motors Using Fuzzy Logic And Self Tuning Fuzzy PI Speed Controls", The Arabian journals for science and engineering, Vol. 33, No. 1B, 153177.

[6] Suparoek, K. Vittaya, T. (2010), "Design of PI Controller Using MRAC Techniques for Coupled-Tanks Process", International Conference on Controls, Automation and System, 485-490.

[7] Chatchaval, P. Tianchai, S. (2009), "Decentralized Fuzzy Logic Controller for TITO Coupled Tanks Process", CROS-SICE International Joint Conference, 2862-2866.

[8] Tianchai, S. Arjin, N. (2007), "Design 2-DOF PI Controller with Decoupling for Coupled-Tank Process", International Conference on Control Automation and Systems, 339-344.
[9] Laubwald, I. (1998), Coupled Tank system 1, England: Visiting-Scientist, Control System Principles.

[10] Muhammad, U.K. Muhammad, B.K. (2009), "Liquid level Control of Nonliear Coupled Tanks system using Linear Model Predictive Control", Proceeding of IEEE, International Conference on Control Aplications, 1-5 